\title{
Association Between Depression and Recurrence of Peptic Ulcer Disease in Older Chinese Patients after Helicobacter Pylori Eradication: A Three-Year Study
}

\author{
Wenni Chen, Yu Yu, Ruirui Xu, Hui Han, Gengzhen Chen* \\ Shantou University Medical College, Shantou, China
}

\section{Article Info}

\section{Article Notes}

Received: July 5, 2019

Accepted: August 5, 2019

\section{*Correspondence:}

Dr. Gengzhen Chen, Shantou University Medical

College, Shantou, China; Email: gzchen12@stu.edu.cn; chengengzhen@126.com.

(C) 2019 Chen G. This article is distributed under the terms of the Creative Commons Attribution 4.0 International License.

\section{Keywords}

Older Chinese People

Depression

Peptic Ulcer Recurrence
Abstract

Background: Both Helicobacter pylori-infected peptic ulcer disease (PUD) and depression are common in older adults. Although $\mathrm{H}$. helicobacter eradication has significantly reduced the risk of PUD recurrence, it remains unknown whether such therapy achieves comparable effect among older patients with and without depression.

Aim: To compare PUD recurrence rates in depressed and non-depressed older patients after successful $H$. pylori eradication, and to evaluate the prospective effect of self-reported and diagnosed depression on PUD recurrence.

Methods. 978 older patients with previous H. pylori-infected PUD were included after $H$. pylori eradication, and followed for up to 36 months. Using endoscopic examination, PUD recurrence rates among depressed and nondepressed older patients were compared. Multivariate logistic regression was performed to ascertain the prospective relationship between depression and PUD recurrence.

Results: PUD recurrence rate was higher in patients with self-reported depression (10.9\%) than those without (6.2\%). Apart from self-reported depression (OR 2.418 (1.232, 4.989), other significant predictors of PUD recurrence included $H$. pylori reinfection $(O R 2.815(1.198,4.687)$, cigarette smoking (OR $2.318(1.238,4.862)$, excessive alcohol drinking (OR 2.287 (1.118, 4.677), high green tea consumption (OR 2.107 (1.025, 4.325), regular ingestion of acetaminophen (OR $2.273(1.238,4.218)$ and NSAIDs (OR 3.341 (2.174, $5.187)$, as well as regular (OR $3.372(2.087,5.298)$, occasional (OR $3.096(2.032$, 5.162), and infrequent aspirin consumption (OR 2.645 (1.218, 4.562). Similar results were yielded on the association between diagnosed depression and PUD recurrence.

Conclusion: PUD recurrence following $H$. pylori eradication is higher in depressed than in non-depressed older patients. PUD recurrence is also attributed by other clinical and behavioral factors. Results of this study sheds lights on the pathways underlying the association between multidimensional factors and PUD recurrence, which provides important implication for clinical practice in geriatric settings.

\section{Introduction}

Depression is a stress-related mood disorder with a chronic course of emotional dysregulation and depressive cognition ${ }^{1}$ that affects approximately $14.3 \%$ of the total global older population ${ }^{2}$. Peptic ulcer disease (PUD) is defined as peptic injury of the digestive tract that leads to mucosal break reaching the submucosa, which usually occurs in the stomach and/or proximal duodenum ${ }^{3}$. Although the role of psychological factors in PUD formation and relapse has generally been ignored ${ }^{4}$, recent clinical evidence 
revealed that depression may contribute to PUD through disturbing hypothalamic-pituitary-adrenal (HPA) axis and dysregulating corticosterone, which is ulcerogenic under continuous and prolonged stress ${ }^{5}$. Likewise, empirical studies have also reported that individuals with depression are at a higher risk of PUD ${ }^{6-8}$ and infection of helicobacter pylori (H. pylori) ${ }^{9}$, which is a gram-negative bacterial pathogen associated with various gastroduodenal complications such as chronic gastritis, intestinal metaplasia, gastric cancer, and PUD $^{3}$. H. pylori infection was found to increase with age, plausibly due to the poor sanitary and socioeconomic conditions of this age cohort ${ }^{10}$. Recent literature suggests that $H$. pylori is present in over $70 \%$ of the older patients with PUD ${ }^{11}$ and is linked to an elevated risk of PUD recurrence ${ }^{12}$. Clinical trials further indicated that rate of PUD recurrence among $\mathrm{H}$. pyloriassociated PUD patients following $H$. pylori eradication therapy ranged from 5 to $20 \%^{10,13,14}$, in comparison to the rate of over $50 \%$ documented in non-eradicated patients ${ }^{15}$. Nevertheless, recent evidence that only reliance on $H$. pylori eradication therapy was insufficient to prevent PUD recurrence ${ }^{13}$ implies the possibility of co-factors and alternative pathways underlying this process. Although depression has been rated as a potential contributor to PUD, it remains unknown whether it also plays a part in PUD recurrence or whether $H$. pylori eradication therapy achieves comparable effect on PUD recurrence among depressed and non-depressed older patients.

There are other behavioral and clinical variables that may also influence PUD recurrence. Polyphenols from green tea, a widely consumed beverage in East Asia, has been found to not only accelerate ulcer healing but also provide gastroprotection against various ulcerogens ${ }^{16}$. Alcohol and cigarette consumption is a common way of self-medication among patients with depression ${ }^{8}$. Although some studies reported abnormal mucosal barriers and PUD recurrence associated with such substance use, these results were not replicated in other studies ${ }^{13,17}$. Among clinical variables, Nonsteroidal Antiinflammatory Drugs (NSAIDs) and aspirin were identified to enhance the risk of PUD and its recurrence ${ }^{18}$ by inhibiting cyclooxygenase 1 (COX-1)-derived prostaglandin synthesis and damaging gastroduodenal mucosa ${ }^{3,19}$. Acetaminophen is therefore often prescribed as an alternative analgesic to many indications, as its analgesic and antipyretic actions resemble those of NSAIDs and aspirin. However, the effect of acetaminophen on PUD recurrence has not been reported.

Despite an elevated susceptibility of older adults to gastroduodenal diseases such as PUD in older adults and their detrimental impact on this population, there is lack of empirical data analyzing this geriatric issue in exiting literature. In view of a growing older population worldwide and the high risk of PUD complications such as hemorrhage, perforation, and mortality in older patients, new empirical data are urgently needed to address this biopsychosocial health problem. This study therefore aims to identify the prospective association between depression and PUD recurrence while considering an array of behavioral and clinical confounders. Specifically, this study hypothesized that clinical diagnosis of and self- reports of depression will have a positive impact on subsequent PUD recurrence in older patients.

\section{Methods}

Older patients aged 50 or above with $H$. pylori-infected gastric and/ or duodenal ulcer were included in baseline study. Older patients with cognitive impairment, malignant tumors, cardiovascular disease, impaired kidney or liver functioning, previous $\mathrm{H}$. pylori-eradication treatment, previous gastric and duodenal operation, Zollinger-Ellison syndrome and who had received anti-ulcer treatment (acid inhibitors: H2-receptor antagonists, proton pump inhibitors; mucosal protective drugs: sucralfate, bismuth salt antibiotics) over the past three months were excluded.

\section{Baseline}

This study was a prospective and comparative trial. A gastroenterologist from each selected hospitals with equivalent education background and experiences conducted all endoscopic examinations, using the same type of endoscope (GIF-XQ260, Olympus Optical Co., Ltd, Tokyo, Japan). Positive H. pylori infection was determined by positive rapid urease test (Ballard Medical Products, Draper, UT, U.S.A.) and results of histological examination. Severities of inflammation were examined using the Sydney System $^{21}$. Of the 1,425 older patients meeting recruitment criteria, 996 gave informed consent after being briefed on the study purpose and confidentiality issues. A 10-day antipylori treatment with esomeprazole $20 \mathrm{mg}$ bid (two time per day) + amoxicillin 1000 mg bid + clarithromycin 500 mg bid was performed on the patients enrolled at baseline ( $\mathrm{n}=1,172$ ). Subsequently, a 4-week anti-ulcer therapy with omeprazole $20 \mathrm{mg}$ bid was given. Confirmation test was conducted 4 weeks after discontinuation of antiulcer therapy, to avoid false-negative results. Negative results on rapid urease test were considered as successful eradication of $\mathrm{H}$. pylori. Healed ulcers were confirmed using histological examination. Detailed description for the performance of endoscopic examination and RUT test can be found elsewhere ${ }^{22}$.

\section{Follow-up}

A total of 1,056 older patients with H. pylori eradicated and peptic ulcer healed by the end of 2014 were included in the follow-up study. Four weeks after the eradication of H. pylori and healing of PUD, these patients were followed 
every six months for 3 years. During follow-up period, patients who ingested anti-ulcer medications for $\geq 3$ days were excluded $(n=79)$. Description of the sample flow for this study can be found in Figure 1. During follow-up period, peptic ulcer symptoms, such as burning stomach pain, bloating, feeling of fullness, dyspepsia, acid reflux, nausea, and heartburn, were documented at each visits. All the patients who were included in the follow-up study were checked for $H$. pylori reinfection and PUD recurrence at six months intervals, using different methods depending on the presence and absence of PUD symptoms. All the patients with these symptoms persisting for over a week were instructed to have an endoscopic examination together with rapid urease test and pathological examination to determine recurrence of peptic ulcer and reinfection of $H$. pylori. In particular, pathological analysis served as the validation check in addition to RUT and only patients who were screened negative for both RUT and pathological analysis were considered as being free from H. pylori reinfection. Those without these symptoms were given Carbon13-labelled urea breath test (Carbon13UBT) to determine $H$. pylori reinfection. Based on previous experience, a sample size of 858 was required to achieve a statistical power of 0.9 to detect an effect size of 0.2 at a probability level of 0.05 . This study was approved by the ethics committee of the authors' affiliated institution.

\section{Measurements}

\section{Outcome variable}

The outcome variable was recurrent PUD.

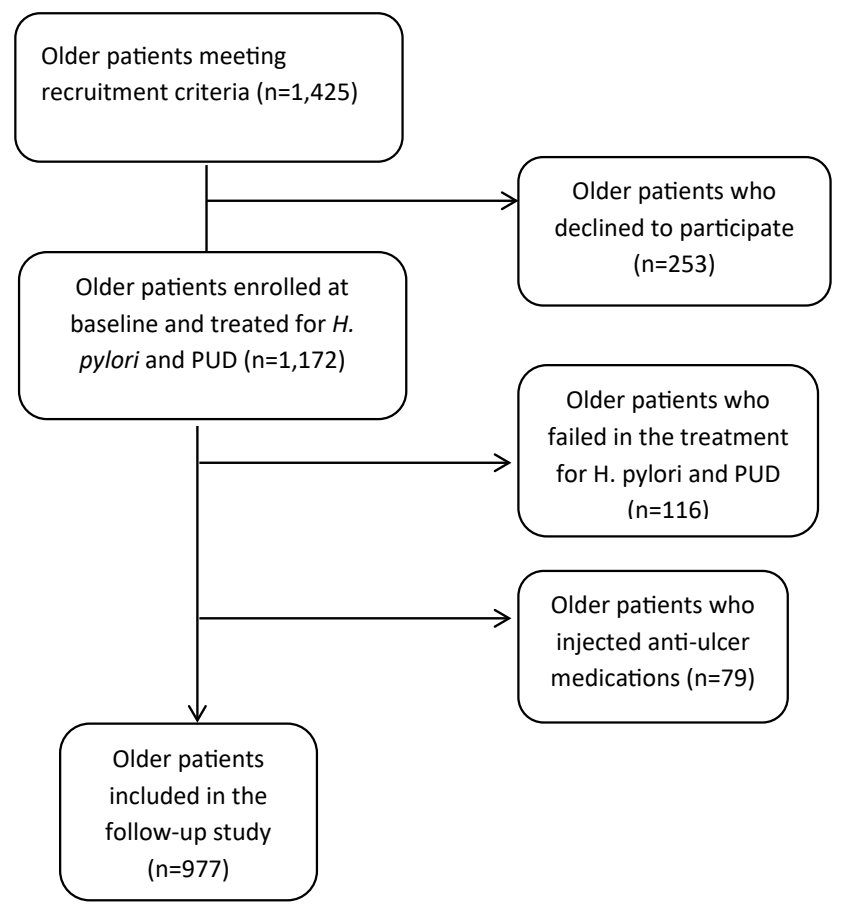

Figure 1: Sample flow of the study.

\section{Major independent variable}

We included as the major independent variable only depression with the first onset prior to the end point, which is the date of PUD recurrence, failure to follow-up, death, or the end of 2017. Self-reported depression was measured using the depression subscale of the Hospital Anxiety and Depression Scale (HADS-D) ${ }^{22}$. A cut-off score of $\geq 8$ was a clinical threshold to define depression ${ }^{22}$. The HADS-D achieved an internal consistency $\alpha$ of 0.665 in this study. Information regarding clinical diagnosis of depression was obtained from the patients' medical records. Diagnosis of depression was made by geriatric psychiatrists based on Hamilton Depression Rating Scale, where a score of $\geq$ was considered having a clinical diagnosis of depression ${ }^{23}$. Data of diagnosis and selfreports of depression were collected at baseline.

\section{Confounding variables}

Medication history included ingestion of NSAIDs, acetaminophen, and aspirin within 6 months before the end-point. The amount and duration of ingestion of these medications were grouped into three categories, including often ( $>1$ tablet/day for $\geq 7$ days or $>1$ tablet/2 day for $\geq$ 14 days), occasionally (1 tablet/day for 3-7 days), and seldom ( $\leq 1$ tablet/day for $\leq 3$ days). Positive cigarette smoking was defined as $\geq 20$ cigarettes/ week. Statuses of alcohol consumption was classified into nil, moderate ( $\leq$ $175 \mathrm{~g} /$ week for men and $\leq 105 \mathrm{~g}$ for women), and excessive $(>175 \mathrm{~g} / \text { week for men and }>105 \mathrm{~g} / \text { week for women })^{24}$ Green tea leaves consumption was categorized into nil, low (1-100g/month), moderate (101- $200 \mathrm{~g} /$ month), moderatehigh (201-300g/month), and high (>300g/month).

\section{Analytic plan}

SPSS was used for data analysis. Prevalence (\%) and mean (SDs) were assessed for major categorical and continuous variables respectively. Rates of peptic ulcer recurrence and $H$. pylori reinfection were recorded. In addition, a series of logistic regression models were applied with peptic ulcer recurrence as outcome variable and selfreported depression as the major independent variable. The core model (Model 1) was adjusted for age and gender.

H. pylori reinfection (biological factor) was included in Model 2. Behavioral factors as such cigarette smoking, alcohol consumption, and tea drinking were added into Model 3, and medication types (NSAIDs, acetaminophen, and aspirin) and frequency (often, occasionally, and seldom) in Block 4. All above models were repeated using diagnosed depression as the major independent variable. Multicollinearity diagnoses were performed prior to conducting logistic regression.

\section{Results}

Between January 2012 to October 2014, a total of 1589 
patients presenting peptic ulcer symptoms meeting our inclusion criteria were referred and 1488 gave informed consent after being briefed on the study and confidentiality issues. These patients consecutively received endoscopic examination and rapid urease test and 1118 were screened positive for both peptic ulcer and $H$. pylori infection, therefore included in baseline trial. These patients received a 10-day anti-pylori treatment and subsequently a 4-week anti-ulcer therapy. By the end of 2014, 1028 (91.9\%) patients obtained successful eradication of $H$. pylori and healing of peptic ulcer
(90 patients failed due to incomplete therapy, intractable ulcer, or side effect of medications) and were followed for 36 months. During the 36-month follow-up period, 50 patients were excluded. Reasons included death $(\mathrm{N}=1)$, gastric or duodenal operations $(\mathrm{N}=6)$ presence of cardiovascular disease $(\mathrm{N}=28)$, malignant tumor $(\mathrm{N}=9)$, dementia $(\mathrm{N}=3)$, and failure of contact $(\mathrm{N}=3)$. Finally 978 patients completed follow-up study. No significant differences were observed between participants and non-participants in terms of age $(t=3.710, p=0.201)$ and gender $\left(X^{2}=0.005, p=0.944\right)$.

Table 1. Sample characteristics and endoscopic findings at follow-up

\begin{tabular}{|c|c|c|c|c|c|c|c|}
\hline Demographics & Total & $\begin{array}{l}\text { Depression } \\
\text { (self-reports) }\end{array}$ & $\begin{array}{c}\text { Non-depression } \\
\text { (self-reports) }\end{array}$ & T test $/ \chi^{2}(p)$ & $\begin{array}{l}\text { Depression } \\
\text { (diagnosis) }\end{array}$ & $\begin{array}{c}\text { Non-depression } \\
\text { (diagnosis) }\end{array}$ & $T$ test $/ \chi^{2}(p)$ \\
\hline Age & $63.57 \pm 9.86$ & $63.28 \pm 10.08$ & $63.79 \pm 9.69$ & -0.658 & $65.21 \pm 10.86$ & $62.80 \pm 9.71$ & -.616 \\
\hline Gender & & & & 1.519 & & & .816 \\
\hline Male & $513(52.5 \%)$ & $129(54.2 \%)$ & $391(52.8 \%)$ & & $105(54.7 \%)$ & $404(51.4 \%)$ & \\
\hline Female & $464(47.5 \%)$ & $109(45.8 \%)$ & $349(47.2 \%)$ & & 87 (45.3\%) & $382(48.6 \%)$ & \\
\hline \multicolumn{8}{|l|}{ Endoscopic findings } \\
\hline H. pylori reinfection & $96(9.8 \%)$ & $34(14.3 \%)$ & $62(8.4 \%)$ & $9.819 * *$ & $28(14.6 \%)$ & $68(8.7 \%)$ & $9.658 * *$ \\
\hline Ulcer recurrence & $70(7.2 \%)$ & $24(10.1 \%)$ & $46(6.2 \%)$ & $8.862^{*}$ & $31(16.1 \%)$ & $39(5.0 \%)$ & $9.508 * *$ \\
\hline Pre-existing ulcer locations & & & & 1.807 & & & 2.655 \\
\hline Gastric ulcer & $380(38.8 \%)$ & $94(39.5 \%)$ & $286(38.6 \%)$ & & $68(35.4 \%)$ & $312(39.7 \%)$ & \\
\hline Duodenal ulcer & $569(58.2 \%)$ & $138(58.0 \%)$ & $431(58.3 \%)$ & & $118(61.5 \%)$ & $451(57.4 \%)$ & \\
\hline Gastric-duodenal ulcer & $29(3.0 \%)$ & $6(2.5 \%)$ & $23(3.1 \%)$ & & $6(3.1 \%)$ & $23(2.9 \%)$ & \\
\hline \multicolumn{8}{|l|}{ Medication used } \\
\hline Acetaminophen & $198(20.2 \%)$ & $62(26.0 \%)$ & $136(18.4 \%)$ & $4.175^{*}$ & $57(29.7 \%)$ & 141 (17.9\%) & $4.277^{*}$ \\
\hline Regularly & $34(3.5 \%)$ & $10(4.2 \%)$ & $24(3.2 \%)$ & & $9(4.7 \%)$ & $25(3.2 \%)$ & \\
\hline Occasionally & 46 (4.7\%) & $14(5.9 \%)$ & $32(4.3 \%)$ & & $12(6.3 \%)$ & $34(4.3 \%)$ & \\
\hline Seldom & $118(12.1 \%)$ & $38(16.0 \%)$ & $80(10.8 \%)$ & & $36(18.8 \%)$ & $82(10.4 \%)$ & \\
\hline NSAID & $218(22.3 \%)$ & $62(26.0 \%)$ & $156(21.1 \%)$ & $3.958 *$ & $48(25.0 \%)$ & $170(21.6 \%)$ & $3.941 *$ \\
\hline Regularly & $38(3.9 \%)$ & $10(4.2 \%)$ & $28(3.8 \%)$ & & $8(4.2 \%)$ & $30(3.8 \%)$ & \\
\hline Occasionally & $52(5.3 \%)$ & $15(6.3 \%)$ & 37 (5.3\%) & & $12(6.3 \%)$ & 40 (5.1\%) & \\
\hline Seldom & $128(13.1 \%)$ & 37 (15.5\%) & $91(12.3 \%)$ & & $28(14.6 \%)$ & $100(12.7 \%)$ & \\
\hline Steriohormone & $135(13.8 \%)$ & $36(14.7 \%)$ & 99 (11.2\%) & 3.018 & $32(16.7 \%)$ & $103(11.6 \%)$ & 2.436 \\
\hline Regularly & $29(3.0 \%)$ & $9(3.8 \%)$ & $20(2.7 \%)$ & & $8(4.2 \%)$ & $21(2.7 \%)$ & \\
\hline Occasionally & $38(3.9 \%)$ & $10(4.2 \%)$ & $28(3.8 \%)$ & & $9(4.7 \%)$ & $29(3.7 \%)$ & \\
\hline Seldom & $68(7.0 \%)$ & $17(7.1 \%)$ & 51 (6.9\%) & & $15(7.8 \%)$ & $53(6.7 \%)$ & \\
\hline Aspirin & 109 (11.1\%) & $31(13.0 \%)$ & $78(10.5 \%)$ & 2.582 & $27(15.1 \%)$ & $82(10.3 \%)$ & 3.036 \\
\hline Regularly & $23(2.4 \%)$ & $6(2.5 \%)$ & $17(2.3 \%)$ & & $5(2.6 \%)$ & $18(2.3 \%)$ & \\
\hline Occasionally & 38 (3.9\%) & $11(4.6 \%)$ & $27(3.6 \%)$ & & $10(5.2 \%)$ & $28(3.6 \%)$ & \\
\hline Seldom & $48(4.9 \%)$ & $14(5.9 \%)$ & $34(4.6 \%)$ & & $12(6.3 \%)$ & $36(4.6 \%)$ & \\
\hline \multicolumn{8}{|l|}{ Behavioral factors } \\
\hline Cigarette smoking & $268(27.4 \%)$ & $82(34.5 \%)$ & $186(25.1 \%)$ & $4.887^{*}$ & $72(37.5 \%)$ & $196(24.9 \%)$ & $5.018^{*}$ \\
\hline Alcohol consumption & $85(8.7 \%)$ & $32(13.4 \%)$ & $53(7.2 \%)$ & $4.238 *$ & $28(14.6 \%)$ & $57(7.3 \%)$ & $4.889 *$ \\
\hline Moderate & $61(6.2 \%)$ & $23(9.7 \%)$ & $38(5.1 \%)$ & & $21(10.9 \%)$ & $40(5.1 \%)$ & \\
\hline Excessive & $24(2.5 \%)$ & $9(3.8 \%)$ & $15(2.0 \%)$ & & $7(3.6 \%)$ & $17(2.2 \%)$ & \\
\hline Green tea consumption & 737 (75.4\%) & $179(75.2 \%)$ & $556(75.1 \%)$ & .121 & 144 (75.0\%) & $593(75.4 \%)$ & .189 \\
\hline Low & $288(29.4 \%)$ & $72(30.3 \%)$ & $216(29.2 \%)$ & & $58(30.2 \%)$ & $230(29.3 \%)$ & \\
\hline Moderate & $209(21.4 \%)$ & $50(21.0 \%)$ & $159(21.5 \%)$ & & $39(20.3 \%)$ & $170(21.6 \%)$ & \\
\hline Moderate-high & $158(16.2 \%)$ & $41(17.2 \%)$ & $117(15.8 \%)$ & & $31(16.1 \%)$ & $127(16.2 \%)$ & \\
\hline High & $82(8.4 \%)$ & $16(6.7 \%)$ & $66(8.9 \%)$ & & $16(8.3 \%)$ & $66(8.4 \%)$ & \\
\hline
\end{tabular}

Data presented as number (\%) or mean (SD)

H. pylori: Helicobacter pylori

NSAID: Nonsteroidal Antiinflammatory Drugs 
Table 2. Endoscopic findings for patients with recurrent peptic ulcers $(N=70)$.

\begin{tabular}{|c|c|c|c|c|c|c|c|}
\hline & Total & $\begin{array}{c}\text { Depression } \\
\text { (self-reports) }\end{array}$ & $\begin{array}{c}\text { Non-depression } \\
\text { (self-reports) }\end{array}$ & $T$ test $/ \chi^{2}(p)$ & $\begin{array}{l}\text { Depression } \\
\text { (diagnosis) }\end{array}$ & $\begin{array}{l}\text { Non-depression } \\
\text { (diagnosis) }\end{array}$ & $T$ test $/ \chi^{2}(p)$ \\
\hline Peptic ulcer recurrence & $70(7.2 \%)$ & $24(10.1 \%)$ & $46(6.2 \%)$ & & $31(16.1 \%)$ & $39(5.0 \%)$ & \\
\hline Recurrent ulcer location & & & & $.093(.760)$ & & & $.907(.341)$ \\
\hline Same or adjacent location & $68(97.1 \%)$ & $23(95.8 \%)$ & $45(97.8 \%)$ & & $30(96.8 \%)$ & $38(97.4 \%)$ & \\
\hline Different locations & $2(2.9 \%)$ & $1(4.2 \%)$ & $1(2.2 \%)$ & & $1(3.2 \%)$ & $1(2.6 \%)$ & \\
\hline Ulcer size (cm) & $0.9 \pm 0.5$ & $1.0 \pm 0.5$ & $0.9 \pm 0.5$ & $.339(.499)$ & $1.0 \pm 0.6$ & $0.9 \pm 0.5$ & $.676(.499)$ \\
\hline Number of recurrent ulcers & $1.3 \pm 0.5$ & $1.3 \pm 0.5$ & $1.3 \pm 0.5$ & $1.887(.098)$ & $1.3 \pm 0.5$ & $1.3 \pm 0.5$ & $1.986(.087)$ \\
\hline Bleeding of recurrent ulcers & $8(11.4 \%)$ & $3(12.5 \%)$ & $5(10.9 \%)$ & $.666(.717)$ & $3(9.7 \%)$ & $5(12.8 \%)$ & $.090(.764)$ \\
\hline Relapse time & $18.38 \pm 9.88$ & $17.98 \pm 10.09$ & $18.87 \pm 8.91$ & $4.225(.000)$ & $17.31 \pm 10.18$ & $19.07 \pm 8.62$ & $4.313(.000)$ \\
\hline
\end{tabular}

Data presented as number (\%) or mean (SD)

\section{Sample characteristics}

The majority of patients at follow-up were male $(52.5 \%$, $\mathrm{N}=513)$, with a mean age of 63.57 years $(\mathrm{SD}=9.86)$. No significant differences were observed in terms of age, gender, previous ulcer locations, and tea consumption in patients with and without depression. Compared to others, patients who reported depression were more likely to have $\mathrm{H}$. pylori reinfection $\left(\chi^{2}=9.819, \mathrm{p}<.01\right)$, consume acetaminophen $\left(\chi^{2}=7.715, \mathrm{p}<.05\right)$, NSAIDs $\left(\chi^{2}\right.$ $=7.411, \mathrm{p}<.05)$, aspirin $\left(\chi^{2}=4.582, \mathrm{p}<.05\right)$, cigarette $\left(\chi^{2}\right.$ $=4.887, \mathrm{p}<.05)$, and alcohol $\left(\chi^{2}=4.238, \mathrm{p}<.05\right)$. Patients with diagnosed depression had a higher risk of $\mathrm{H}$. pylori reinfection $\left(\chi^{2}=12.658, p<.001\right)$. They were also more prone to consuming acetaminophen $\left(\chi^{2}=7.078, p<.01\right)$, NSAIDs $\left(\chi^{2}=6.958, \mathrm{p}<.05\right)$, and aspirin $\left(\chi^{2}=4.582, \mathrm{p}<\right.$ $.05)$, cigarette $\left(\chi^{2}=5.018, \mathrm{p}<.05\right)$, and alcohol $\left(\chi^{2}=4.889\right.$, $\mathrm{p}<.05)$.

\section{Depression and PUD recurrence}

During follow-up period, 108 patients presented peptic ulcer symptoms, including stomach pain $(\mathrm{N}=38)$, feeling of fullness or bloating $(\mathrm{N}=30)$, dyspepsia $(\mathrm{N}=21)$, acid reflux $(\mathrm{N}=10)$, nausea $(\mathrm{N}=6)$, and heartburn $(\mathrm{N}=3)$. These patients were referred for endoscopic examination and 70 were found recurrent PUD. However, no significant differences were found in locations, numbers, sizes, and bleeding of the recurrent ulcer (s) between patients with and without depression. Regarding peptic ulcer recurrence, the entire sample yields an overall cumulative ulcer recurrence rate of $7.2 \%$ in during the 36-month follow-up period, with an annual rate of $2.4 \%$. Specifically, 36-month cumulative recurrence rate was significantly higher in patients with self-reported depression (10.9\%) than in their counterparts free from depression (6.2\%), generating annual recurrence rates of $3.63 \%$ versus $2.07 \%$. Using clinical diagnosis to define depression, depressed patients $(16.1 \%)$ were also significantly more vulnerable to ulcer recurrence than the non-depressed cohort (5.0\%), with annual recurrence rates of $5.37 \%$ versus $1.67 \%$. Multivariate logistic regression further identified that patients with diagnosed (OR 2.287 (1.198, 5.062) were over two times more likely to have recurrent peptic ulcer than their non-depressed counterparts, after adjusting for clinical and psychosocial variables. Similarly, self-reported depression was also associated with an increased odd of PUD recurrence (OR $2.418(1.232,4.989)$. To further verify result regarding the association between self-reported depression and PUD recurrence, we have repeated the analysis by using self-reported depression as a continuous variable. The result consistently showed that a greater severity of self-reported depression increased the risk of PUD recurrence (OR $2.086(1.183,4.628)$ ).

\section{Confounders and PUD recurrence}

In the fully adjusted model (Table 3) with self-reported depression as the major independent variable, apart from H. pylori reinfection (OR 2.815 (1.198, 4.687), PUD recurrence was also positively associated with behavioral factors as such cigarette smoking (OR $2.318(1.238,4.862)$, excessive alcohol drinking (OR 2.287 (1.118, 4.677), and a high level of green tea consumption (OR 2.107 (1.025, 4.325). However, alcohol drinking in moderation (OR $0.843(0.738,0.979)$, as well as low (OR $0.762(0.652$, $0.886)$ to moderate levels of green tea consumption (OR $0.701(0.598,0.887)$ were found to reduce the risk of PUD recurrence by approximately 15\%-20\%. Regular ingestion of acetaminophen (OR $2.273(1.238,4.218)$ and NSAIDs (OR $3.341(2.174,5.187)$ ), as well as regular (OR 3.372 $(2.087,5.298))$, occasional (OR $3.096(2.032,5.162))$, and infrequent consumption of aspirin (OR $2.645(1.218,4.562)$ all contributed to a greater risk of PUD recurrence. Results were similar in the full adjustment model with diagnosed depression as the major independent variable (Table 4).

\section{Discussion}

This is the first longitudinal study that examined rate and psychological risk factor of PUD recurrence in $\mathrm{H}$. pyloriinfected ulcer older patients who had obtained successful H. pylori eradication. A 10-day course of proton pump inhibitor-based triple therapy and a 4-week anti-ulcer therapy were used and $91.4 \%$ of the patients enrolled had H. pylori eradicated and PUD healed, which is comparable to 
Table 3. Association between diagnosed depression and peptic ulcer recurrence.

\begin{tabular}{|c|c|c|c|c|}
\hline & Model 1 & Model 2 & Model 3 & Model 4 \\
\hline \multicolumn{5}{|l|}{ Demographics } \\
\hline Age & $.949 * * *(0.927,0.971)$ & $.960 * *(0.936,0.984)$ & $.956 * *(0.932,0.980)$ & $.788(.426,1.456)$ \\
\hline Gender & $.984(0.608,1.592)$ & $1.124(0.685,1.845)$ & $1.021(0.613,1.698)$ & $.991(.966,1.018)$ \\
\hline \multicolumn{5}{|l|}{ Biological factor } \\
\hline H. pylori reinfection & & $4.282 * * *(3.269,5.987)$ & $3.708 * *(2.306,5.318)$ & $2.872 * *(1.618,4.882)$ \\
\hline \multicolumn{5}{|l|}{ Behavioral factors } \\
\hline Smoking & & & $2.146 *(1.128,3.628)$ & $2.318 *(1.238,4.862)$ \\
\hline \multicolumn{5}{|l|}{ Alcohol consumption } \\
\hline Excessive & & & $2.490 * *(1.358,4.689)$ & $2.287 *(1.118,4.677)$ \\
\hline Moderate & & & $0.829 * *(0.727,0.958)$ & $0.843 *(0.738,0.979)$ \\
\hline Nil & & & 1.000 & 1.000 \\
\hline \multicolumn{5}{|l|}{ Green tea consumption } \\
\hline High & & & $2.118 * *(1.039,3.417)$ & $1.897 *(1.028,3.575)$ \\
\hline Moderate-high & & & $1.802(0.452,7.181)$ & $2.223(.665,7.430)$ \\
\hline Moderate & & & $0.683 *(0.591,0.828)$ & $0.701 *(0.598,0.887)$ \\
\hline Low & & & $0.726 * *(0.623,0.838)$ & $0.762 *(0.652,0.886)$ \\
\hline Nil & & & 1.000 & 1.000 \\
\hline \multicolumn{5}{|l|}{ Medication used } \\
\hline \multicolumn{5}{|l|}{ Acetaminophen } \\
\hline Regularly & & & & $2.273^{* * *}(1.238,4.218)$ \\
\hline Occasionally & & & & $2.085(0.646,6.731)$ \\
\hline Seldom & & & & $1.950(0.658,5.311)$ \\
\hline Never & & & & 1.000 \\
\hline \multicolumn{5}{|l|}{ NSAID } \\
\hline Regularly & & & & $3.341 * * *(2.174,5.187)$ \\
\hline Occasionally & & & & $2.806(0.858,4.859)$ \\
\hline Seldom & & & & $1.996(0.588,5.926)$ \\
\hline Never & & & & 1.000 \\
\hline \multicolumn{5}{|l|}{ Aspirin } \\
\hline Regularly & & & & $3.372 * *(2.087,5.298)$ \\
\hline Occasionally & & & & $3.096 * *(2.032,5.162)$ \\
\hline Seldom & & & & $2.645^{* * *}(1.218,4.562)$ \\
\hline Never & & & & 1.000 \\
\hline \multicolumn{5}{|l|}{ Psychological factor } \\
\hline Diagnosed depression & $3.802 * *(2.310,5.825)$ & $2.958 * *(1.672,5.318)$ & $2.786 * *(1.432,5.138)$ & $2.187^{* *}(1.098,4.962)$ \\
\hline
\end{tabular}

Notes : Hosmer-Lemeshow goodness of fit test: $X^{2}=4.958, d f=7, p=0.665$; Nagelkerke $R^{2}=0.461$

H. pylori: Helicobacter pylori

NSAID: Nonsteroidal Antiinflammatory Drugs

previous research ${ }^{13}$. This study yields an overall cumulative PUD recurrence rate of $7.2 \%$ for the entire sample with successful $\mathrm{H}$. pylori eradication over the 36 -month followup period, giving an annual rate of $2.4 \%$, which is higher than the annual rate of $1.9 \%$ documented in a Japanese cohort followed for four years ${ }^{14}$, but lower than that based on a 2-year study of a clinical sample in Taiwan (5.49\%) $)^{13}$. Discrepancy in recurrence rates across studies is possibly attributed to methodological variation (i.e. length of observation period, sampling, and patient selection).

More specifically, our data suggest higher 36-month recurrence rates in patients who reported depressive symptoms $(10.9 \%)$ and who had a clinical diagnosis of depression (16.1\%). Our results further showed that depression (both self-reported and diagnosed) was associated with over 2-fold increased risk of PUD recurrence after adjusting for biological, clinical, behavioral, and demographic confounders, which implies that $\mathrm{H}$. pylori eradication might have weaker protective effect against PUD recurrence in depressed than in nondepressed patients. Despite the lack of existing data investigating the association between depression and PUD recurrence, previous observations have shown a significant increase in the incidence of PUD $^{6}$ and gastric acid secretion ${ }^{5}$ among patients with depression and those without. It is hypothesized that the mechanism connecting depression with peptic ulcer is associated with dysregulation of the hypothalamic-pituitary-adrenal 
Table 4. Association between self-reported depression and peptic ulcer recurrence.

\begin{tabular}{|c|c|c|c|c|}
\hline & Model 1 & Model 2 & Model 3 & Model 4 \\
\hline \multicolumn{5}{|l|}{ Demographics } \\
\hline Age & $.949 * * *(0.927,0.971)$ & $.960 * *(0.936,0.984)$ & $.956 * *(0.932,0.980)$ & $.981(0.954,1.009)$ \\
\hline Gender & $.984(0.608,1.592)$ & $1.124(0.685,1.845)$ & $1.021(0.613,1.698)$ & $1.406(0.779,2.537)$ \\
\hline \multicolumn{5}{|l|}{ Biological factor } \\
\hline H. pylori reinfection & & $4.282 * * *(3.269,5.987)$ & $3.708 * *(2.306,5.318)$ & $2.815^{* *}(1.198,4.687)$ \\
\hline \multicolumn{5}{|l|}{ Behavioral factors } \\
\hline Smoking & & & $2.146 *(1.128,3.628)$ & $2.182 *(1.162,3.588)$ \\
\hline \multicolumn{5}{|l|}{ Alcohol consumption } \\
\hline Excessive & & & $2.490 * *(1.358,4.689)$ & $2.388 * *(1.231,4.598)$ \\
\hline Moderate & & & $0.829 * *(0.727,0.958)$ & $0.836 *(0.732,0.970)$ \\
\hline \multicolumn{5}{|l|}{ Nil } \\
\hline \multicolumn{5}{|l|}{ Green tea consumption } \\
\hline High & & & $2.118 * *(1.039,3.417)$ & $1.908 *(1.026,3.674)$ \\
\hline Moderate-high & & & $1.802(0.452,7.181)$ & $1.551(0.722,3.330)$ \\
\hline Moderate & & & $0.683 *(0.591,0.828)$ & $0.719 *(0.608,0.895)$ \\
\hline Low & & & $0.726 * *(0.623,0.838)$ & $0.738 *(0.626,0.867)$ \\
\hline Nil & & & 1.000 & 1.000 \\
\hline \multicolumn{5}{|l|}{ Medication used } \\
\hline \multicolumn{5}{|l|}{ Acetaminophen } \\
\hline Regularly & & & & $2.234^{* *}(1.186,4.187)$ \\
\hline Occasionally & & & & $1.967(0.867,4.058)$ \\
\hline Seldom & & & & $1.230(0.662,3.338)$ \\
\hline Never & & & & 1.000 \\
\hline \multicolumn{5}{|l|}{ NSAID } \\
\hline Regularly & & & & $3.186 * *(2.130,4.883)$ \\
\hline Occasionally & & & & $2.588 * *(1.566,4.638)$ \\
\hline Seldom & & & & $1.162(0.455,2.874)$ \\
\hline Never & & & & 1.000 \\
\hline \multicolumn{5}{|l|}{ Aspirin } \\
\hline Regularly & & & & $3.038^{* *}(1.818,4.533)$ \\
\hline Occasionally & & & & $2.318 *(1.347,3.584)$ \\
\hline Seldom & & & & $2.237 *(1.266,3.998)$ \\
\hline Never & & & & 1.000 \\
\hline \multicolumn{5}{|l|}{ Psychological factor } \\
\hline Self-reported depression & $3.886 * * *(2.352,5.887)$ & $2.664 * * *(1.406,5.052)$ & $2.539 * * *(1.281,5.033)$ & $2.418 *(1.232,4.989)$ \\
\hline
\end{tabular}

Hosmer-Lemeshow goodness of fit test: $X^{2}=6.248, d f=7, p=0.511$; Nagelkerke $R^{2}=0.473$

H. pylori: Helicobacter pylori

NSAID: Nonsteroidal Antiinflammatory Drugs

(HPA) axis and sympathoadrenal stress response pathways which is linked to depression ${ }^{25}$. HPA dysregulation has also been identified to negatively affect gastroduodenal function, acid secretions, and immune system function ${ }^{26-27}$, potentially increasing biological susceptibility to ulceration, and impairing defense against causative agents, such as $H$. pylori reinfection ${ }^{27}$. Alternatively possible is that depression may elevate the level of cortisol, which is ulcerogenic under stressful circumstances ${ }^{28}$. Furthermore, patients with depression are more likely to digest selective serotonin reuptake inhibitors (SSIR), which has been supported by clinical evidence to deplete serotonin from platelets, potentially leading to lowered serotonin concentration inside the platelets, impaired haemostatic function ${ }^{29}$, delayed plug formation, and inhibition of ulcers healing by the lack of vascular endothelial growth factor ${ }^{30}$.

\section{Strengths}

Our study advances previous research in three aspects. First, this study utilizes prospective data and only included as predictor depression that had first onset prior to PUD recurrence suggesting that depression may be a predictor of PUD recurrence, although future studies with more rigorous experimental design are needed to verify this relationship. Second, depression in this study was based not only on clinicians' diagnosis but also self-reports, which allows for identifying patients with depressive symptoms but had not visited psychological clinics. Third, 
PUD diagnosis in this study was obtained from endoscopic findings, which provided more reliable and valid results than those solely depending on patients' subjective complaints ${ }^{6}$.

\section{Limitations}

Limitations should be noted. First, for economic consideration, endoscopic examination was only performed for patients with possible PUD symptoms rather than all studied patients, which may underestimate PUD recurrence rate. Second, this study did not analyze the effect of concurrent use of NSAIDs, aspirin, and acetaminophen, which might produce additive gastrointestinal toxicity. Third, due to the lack of experimental design, no causal relationship can be confirmed between various predictors and PUD recurrence. In addition, convenience sampling means that the present findings cannot be generalized to other older population. Furthermore, certain potential confounders, such as stressful events, personality trait, family history, or socioeconomic statuses were not included in model testing, as they are unavailable in our database. Finally, although we have speculated that HPA axis may have played a role in the relationship between depression and PUD recurrence, we were not able to further test the effect of dysregulation of HPA axis at this stage, due to the lack of relevant measure in our dataset.

\section{Implication}

This study delineates a prospective and robust relationship between depression, which suggests that endoscopic examination should be included as a routine procedure for depressed patients with previous $H$. pyloriinfected PUD. Psychosocial therapies targeting at depression might also help reduce the odds of PUD recurrence. Identification of other significant predictors means that PUD recurrence is a complex phenomenon attributed to multifaceted factors. Our results that frequent rather than infrequent use of NSAIDs and acetaminophen increased the risk of PUD recurrence implies that physicians should adopt risk-minimizing strategies to evaluate benefits and harms of these drugs and take special precaution when prescribing them to older patients with previous PUD. The predictive effect of aspirin on PUD recurrence suggests that older patients with previous ulcer should avoid aspirin unless under unusual circumstances and rigorous medical supervision. A lowest dose for the shortest period of time might help alleviate some related toxicity. The contradictory effect of alcohol and tea depending on different dosage suggests that these beverages, if consumed with appropriate dosage, may be a convenient and inexpensive way for primary prevention of PUD recurrence.

\section{Conclusion}

This study depends on 3-year longitudinal data to investigate the relationship between depression and PUD recurrence in older patients. Specifically, depression based on self-reports and clinical diagnosis, was found to have a longitudinal impact on subsequent recurrence of PUD. These results, if further replicated in population-based studies, will lead to a new pathway for prevention of PUD recurrence.

\section{References}

1. Smoller JW. The Genetics of Stress-Related Disorders: PTSD, Depression, and Anxiety Disorders. Neuropsychopharmacology REVIEWS. 2016; 41: 297-319.

2. Mayor S. Asking older people two simple questions accurately detects depression risk, study finds. BMJ. 2017; 356.

3. Lanas A, Chan FKL. Peptic ulcer diseases. Lancet. 2017; 390: 613-24

4. Levenstein S, Rosenstock S, Jacobsen RK, et al. Psychological Stress Increases Risk for Peptic Ulcer, Regardless of Helicobacter pylori Infection or Use of Nonsteroidal Anti-inflammatory Drugs. Clinical Gastroenterology and Hepatology, 2015; 13: 498-506.

5. Zhang S, Xu Z, Gao Y, et al. Bidirectional Crosstalk between StressInduced Gastric Ulcer and Depression under Chronic Stress. PLoS ONE. 2012; 7(12): e51148.

6. Scott KM, Alonso J, de Jonge P, et al. Associations between DSM-IV mental disorders and onset of self-reported peptic ulcer in the World Mental Health Surveys. Journal of Psychosomatic Research. 2013; 75: 121-127.

7. Hsu CC, Hsu YC, Chang KH, et al. Depression and the Risk of Peptic Ulcer Disease: A Nationwide Population-Based Study. Medicine. 2015; 94 (51): e2333.

8. Lee YB, Yu J, Choi HH, et al. The association between peptic ulcer diseases and mental health problems A population-based study: a STROBE compliant article. Medicine. 2017; 96: 34-39.

9. Kabeer KK, Ananthakrishnan N, Anand C, et al. Prevalence of Helicobacter Pylori Infection and Stress, Anxiety or Depression in Functional Dyspepsia and Outcome after Appropriate Intervention. Journal of Clinical and Diagnostic Research. 2017; 11 (8): VC11-VC15.

10. Liou JM, Lin JT, Lee YC, et al. Helicobacter Pylori Infection in the Elderly, International Journal of Gerontology. 2008; 2 (4): 145-153.

11. Pilotto A, Franceschi M. Helicobacter pylori infection in older people. World Journal of Gastroenterology. 2014; 20 (21): 6364-6373.

12. Kim JJ, Kim N, Lee BH, et al. Risk Factors for Development and Recurrence of Peptic Ulcer Disease. Korean Journal Gastroenterology. 2010; 56(4): 220-228.

13. Tseng GY, Lin HJ, Fang CT, et al. Recurrence of peptic ulcer in uraemic and non-uraemic patients after Helicobacter pylori eradication: a 2-year study. Alimentary Pharmacology \& Therapeutics. 2007; 26: 925-933.

14. Miwa H, Sakaki N, Sugano K, et al. Recurrent Peptic Ulcers in Patients Following Successful Helicobacter pylori Eradication: A Multicenter Study of 4940 Patients. HELICOBACTER. 2004; 9 (1): 9-16.

15. Leodolter A, Kulig M, Brasch H, et al. A meta-analysis comparing eradication, healing and relapse rates in patients with Helicobacter pylori-associated gastric or duodenal ulcer. Alimentary Pharmacology \& Therapeutics. 2001; 15 (12): 1949-1958.

16. Hoshiyama Y, Kawaguchi T, Miura Y, et al. A prospective study of stomach cancer death in relation to green tea consumption in Japan. British Journal of Cancer. 2002; 87: 309 - 313.

17. Lau Y, Sung J, Hill C, et al. Systematic Review of the Epidemiology of Complicated Peptic Ulcer Disease: Incidence, Recurrence, Risk Factors and Mortality, Digestion. 2011; 84: 102-113. 
18. Crofford LJ. Use of NSAIDs in treating patients with arthritis. Arthritis Research \& Therapy. 2013; 15 (Suppl 3): S2-S12.

19. Shimada Y, Nagahara A, Hojo M, et al. Upper Gastrointestinal Mucosal Injury and Symptoms in Elderly Low-Dose Aspirin Users. Gastroenterology Research and Practice. 2015; 2015, Article ID 252963. http://dx.doi.org/10.1155/2015/252963.

20. Pietroiusti A, Luzzi I, Gomez MJ, et al. Helicobacter pylori duodenal colonization is a strong risk factor for the development of duodenal ulcer. Alimentary Pharmacology \& Therapeutics. 2005; 201: 909-915.

21. Fang B, Yang S, Xu R, et al. Association between poor sleep quality and subsequent peptic ulcer recurrence in older patients with mild cognitive impairment: Examining the role of social engagement. Scientific Report. 2019; 9: 2188. doi: 10.1038/s41598-019-38715-3.

22. Zigmond AS, Snaith RP. The Hospital Anxiety and Depression Scale. Acta Psychiatrica Scandinavica. 1983; 67 (6): 361-370.

23. Zheng YP, Zhao JP, Phillips M, et al. Validity and reliability of the Chinese Hamilton Depression Rating Scale. The British journal of psychiatry : the journal of mental science. 1988; 152: 660-664

24. Lu SJ, Du SM, Ma GS. Development of Alcohol Consumption Standards. Journal of Hygiene Research. 2015; 44 (1): 163-165.

25. Young EA, Abelson JL, Cameron OG. Effect of comorbid anxiety disorders on the hypothalamic-pituitary-adrenal axis response to a social stressor in major depression. Biological Psychiatry. 2004; 56 113-120.

26. Scott KM, Von Korff M, Angermeyer MC, et al. The association of childhood adversities and early onset mental disorders with adult onset chronic physical conditions. Archives of General Psychiatry. 2011; 68: 838-844.

27. Levenstein S. Psychosocial Factors in Peptic Ulcer and Inflammatory Bowel Disease. Journal of Consulting and Clinical Psychology. 2002; 70 (3): 739-750.

28. Bhatia V, Tandon R. Stress and the gastrointestinal tract. Journal of Gastroenterology and Hepatology. 2005; 20: 332-339.

29. de Abajo FJ, Rodríguez LA, Montero D. Association between selective serotonin reuptake inhibitors and upper gastrointestinal bleeding: population based casecontrol study. BMJ. 1999; 319: 1106-1109.

30. Dall M, Schaffalitzky de Muckadell OB, Lassen AT, et al. There is an association between selective serotonin reuptake inhibitor use and uncomplicated peptic ulcers: a populationbased case-control study. Alimentary Pharmacology and Therapeutics. 2010; 32: 1383-1391.

31. Maity P, Biswas K, Roy S, et al. Smoking and the pathogenesis of gastroduodenal ulcer - recent mechanistic update. Molecular and Cellular Biochemistry. 2003; 253: 329-338.
32. Li LF, Chan RL, Lu L, et al. Cigarette smoking and gastrointestinal diseases: The causal relationship and underlying molecular mechanisms (Review). International Journal of Molecular Medicine. 2014; 34 (2): 372-380.

33. Seo JH, Hong SJ, Kim JH, et al. Long-Term Recurrence Rates of Peptic Ulcers without Helicobacter pylori. Gut and Liver. 2016; 10 (5): 719 725 .

34. Liu SY, Han XC, Sun J, et al. Alcohol intake and Helicobacter pylori infection: a dose-response meta-analysis of observational studies. Infectious Diseases. 2016; 48 (4): 303-309.

35. Wallace J. Prostaglandins, NSAIDs, and Gastric Mucosal Protection: Why Doesn't the Stomach Digest Itself?. Physiological Reviews. 2008; 88: $1547-1565$.

36. Garrow D, Delegge MH. Risk Factors for Gastrointestinal Ulcer Disease in the US Population. Digestive Diseases and Sciences. 2010; 55: 6672 .

37. Goodwin RD, Keyes KM, Stein MB, et al. Peptic Ulcer and Mental Disorders Among Adults in the Community: The Role of Nicotine and Alcohol Use Disorders. Psychosomatic Medicine. 2009; 71: 463-468.

38. Stoicov C, Saffari R, Houghton J. Green tea inhibits Helicobacter growth in vivo and in vitro. International Journal of Antimicrobial Agents: 2009; 33 (5): 473-478.

39. Farzaei MH, Abdollahi,M, Rahimi R. Role of dietary polyphenols in the management of peptic ulcer. World Journal of Gastroenterology. 2015; 21(21): 6499-6517.

40. Liszt KI, Ley JP, Lieder B, et al. Caffeine induces gastric acid secretion via bitter taste signaling in gastric parietal cells. PNAS. 2017; 114 (30): E6260-E6269.

41. Goldstein JL, Huang B, Amer F, et al. Ulcer Recurrence in High-Risk Patients Receiving Nonsteroidal Anti-Inflammatory Drugs Plus LowDose Aspirin: Results of a Post Hoc Subanalysis. Clinical Therapeutics. 2004; 26(10): 1637-1643.

42. Fries JF, Bruce B. Rates of serious gastrointestinal events from low dose use of acetylsalicylic acid, acetaminophen, and ibuprofen in patients with osteoarthritis and rheumatoid arthritis. The Journal of Rheumatology. 2003; 30 (10): 2226-2233.

43. Moore N, Scheiman JM. Gastrointestinal safety and tolerability of oral non-aspirin over-the-counter analgesics. Postgraduate Medical Journal. 2018; 8: 1-12.

44. Rahme E, Pettitt D, LeLorier J. Determinants and sequelae associated with utilization of acetaminophen versus traditional nonsteroidal antiinflammatory drugs in an elderly population. Arthritis \& Rheumatism. 2002; 46: 3046-3054. 